\title{
Protease inhibitors decrease lgG shedding from Staphylococcus aureus, increasing complement activation and phagocytosis efficiency
}

\begin{abstract}
Correspondence
Kenji M. Cunnion

cunniokm@evms.edu
\end{abstract}

Received 25 October 2010

Accepted 31 May 2011

\author{
Maria F. Fernandez Falcon, ${ }^{1}$ Charlene G. Echague, ${ }^{1}$ Pamela S. Hair, ${ }^{1}$ \\ Julius O. Nyalwidhe ${ }^{2}$ and Kenji M. Cunnion ${ }^{1,3,4}$ \\ ${ }^{1}$ Department of Pediatrics, Eastern Virginia Medical School, Norfolk, VA, USA \\ ${ }^{2}$ Department of Microbiology and Molecular Cell Biology, Eastern Virginia Medical School, Norfolk, \\ VA, USA \\ ${ }^{3}$ Children's Specialty Group, Norfolk, VA, USA \\ ${ }^{4}$ The Children's Hospital of The King's Daughters, Norfolk, VA, USA
}

\begin{abstract}
Staphylococcus aureus is a major pathogen for immunologically intact humans and its pathogenesis is a model system for evasion of host defences. Antibodies and complement are essential elements of the humoral immune system for prevention and control of $S$. aureus infections. The specific hypothesis for the proposed research is that $S$. aureus modifies humoral host defences by cleaving $\lg G$ that has bound to the bacterial surface, thereby inhibiting opsonophagocytosis. S. aureus was coated with pooled, purified human $\lg G$ and assayed for the shedding of cleaved IgG fragments using ELISA and Western blot analysis. Surface-bound IgG was shed efficiently from $S$. aureus in the absence of host blood proteins. Broad-spectrum protease inhibitors prevented cleavage of $\operatorname{lgG}$ from the $S$. aureus surface, suggesting that staphylococcal proteases are responsible for IgG cleavage. Serine protease inhibitors and cysteine protease inhibitors decreased the cleavage of surface-bound IgG; however, a metalloprotease inhibitor had no effect. Using protease inhibitors to prevent the cleavage of surface-bound IgG increased the binding of complement C3 fragments on the surface of $S$. aureus, increased the association with human neutrophils and increased phagocytosis by human neutrophils.
\end{abstract}

\section{INTRODUCTION}

Staphylococcus aureus is responsible for an array of infections including those of skin and soft tissue, as well as life-threatening invasive infections in normal hosts (ElGilany \& Fathy, 2009; Rogers et al., 2009). Antibiotic treatment of $S$. aureus infections is becoming ever more challenging with the recent emergence of communityassociated meticillin-resistant S. aureus (MRSA) (Klein et al., 2007). Understanding S. aureus evasion of host defences may prove critical in preventing and treating $S$. aureus infections in the future.

IgG plays an essential role in the humoral immune system control of bacterial infections (Brown et al., 1982). One of the important functions of this antibody is opsonizing bacteria and improving their recognition by phagocytic leukocytes (Leijh et al., 1981). IgG can also activate the classical complement pathway leading to additional

Abbreviations: MRSA, meticillin-resistant Staphylococcus aureus; MS/MS, tandem mass spectrometry. opsonization by the complement $\mathrm{C} 3 \mathrm{~b} / \mathrm{iC} 3 \mathrm{~b}$ fragments and the generation of anaphylatoxins (Joiner et al., 1983).

S. aureus utilizes multiple strategies to evade IgG-mediated immune functions. S. aureus protein A is a cell-wall protein that binds IgG via the Fc region, thereby affecting its ability to act as an opsonin (Peterson et al., 1977). Another evasion mechanism utilizes staphylokinase, a bacteriophageencoded protein that activates the serine protease plasmin, enabling the cleavage of IgG (Rooijakkers et al., 2005).

$S$. aureus encodes proteases in three categories: metalloprotease (aureolysin), serine proteases (SspA and SplA, SplB, SplC, SplD, SplE and SplF) and cysteine proteases (SspB and ScpA) (Boles \& Horswill, 2008). Prokesová et al. (1992) purified the serine protease V8 (SspA) from $S$. aureus growth medium and demonstrated that it could cleave human immunoglobulins floating free in solution. They observed that V8 cleaved soluble IgG not only in the hinge region, as described for other bacterial proteases, but also at multiple sites on the antibody molecule. These studies only tested unbound IgG in solution and required 
high enzyme:substrate ratios $(1: 5-1: 20)$ and lengthy incubation times $(4-24 \mathrm{~h})$. At enzyme: substrate ratios of $1: 100 \mathrm{IgG}$, cleavage effects were minimal.

To our knowledge, the experiments described in the current study are the first to elucidate the shedding of $S$. aureus surface-bound IgG. These studies measured the cleavage of surface-bound IgG from S. aureus and evaluated classes of protease inhibitor that could modify $\operatorname{IgG}$ cleavage. These studies assayed whether protease inhibition of IgG shedding modulates IgG-mediated immune functions.

\section{METHODS}

Ethics statement. Healthy human volunteers donated blood under an Institutional Review Board-approved protocol (Eastern Virginia Medical School IRB: 02-06-EX-0216). This blood was used to generate serum and leukocytes for use as reagents. These products were used as reagents only and not to derive information about the donors. All donors provided written informed consent.

Bacterial strains and growth. A well-characterized S. aureus laboratory strain, Newman, was used in all experiments, unless otherwise noted. In some experiments, a clinical MRSA strain, MRSA7, was used that was obtained as a discarded de-identified isolate from a clinical microbiology laboratory (Eastern Virginia Medical School IRB protocol: 06-04-WC-0040). MRSA7 is a community-associated MRSA with a PFGE pattern consistent with strain USA300. Bacteria were grown in Columbia/ $2 \% \mathrm{NaCl}$ broth and incubated at $37^{\circ} \mathrm{C}$ for $2 \mathrm{~h}$ with agitation to mid-exponential phase, unless otherwise stated. For some experiments, S. aureus was gently heat-killed at $70{ }^{\circ} \mathrm{C}$ for $12 \mathrm{~min}$.

Buffers. Buffers used were GVBS ${ }^{2+}$ (Veronal-buffered saline, $0.1 \%$ gelatin, $0.15 \mathrm{mM} \mathrm{CaCl}, 1.0 \mathrm{mM} \mathrm{MgCl}_{2}$ ), EDTA-GVBS ${ }^{2-}$ (Veronalbuffered saline with $0.1 \%$ gelatin, $0.01 \mathrm{M}$ EDTA) and raffinose buffer [15 g raffinose in $44 \mathrm{ml}$ distilled water, $5 \mathrm{ml} 50 \mathrm{mM}$ Tris/ $\mathrm{HCl}(\mathrm{pH}$ 7.5), $1 \mathrm{ml} 1 \mathrm{M} \mathrm{MgCl}_{2}$ ].

Preparation of serum, IgG, complement proteins and protease inhibitors. Normal human serum was prepared from the blood of healthy human volunteers and pooled as described previously (Cunnion et al., 2001). IgG-depleted serum was generated by ProteoPrep spin columns (Sigma-Aldrich) following the manufacturer's protocol.

Purified pooled human IgG (Gammagard; Baxter) was reconstituted at the manufacturer's recommended concentration of $50 \mathrm{mg} \mathrm{ml}^{-1}$. In experiments involving complement or phagocytosis, the IgG was further diluted 1:50 $\left(1 \mathrm{mg} \mathrm{ml}{ }^{-1}\right)$. Purified human complement protein $\mathrm{C} 3$ and polyclonal antibodies directed against human C3 were purchased from CompTech. Complete Mini protease inhibitor cocktail (Roche) was used for broad-spectrum inhibition. The Complete Mini tablet was dissolved in $1.5 \mathrm{ml}$ distilled water. Individual protease inhibitors (PMSF, Pefabloc, aprotinin, E64, Nethylmaleimide and EDTA) were used from the Protease Inhibitors Set (Roche); starting concentrations and buffer dilutions used for each protease inhibitor were as recommended by the manufacturer.

Human IgG binding to and release from $\boldsymbol{S}$. aureus. Washed bacteria $\left(1 \mathrm{ml}\right.$ containing $1 \times 10^{9}$ cells) were combined with $100 \mu \mathrm{l}$ purified IgG $\left(1 \mathrm{mg} \mathrm{ml}^{-1}\right)$ and incubated at room temperature for 5 min. After five washes with EDTA-GVBS ${ }^{2-}$ and centrifugation, the pellets were resuspended in $50 \mu \mathrm{l} \mathrm{PBS}$ and incubated in a water bath at $37^{\circ} \mathrm{C}$ for $30 \mathrm{~min}$, unless otherwise indicated. Supernatants were collected for measurement of IgG fragment release by ELISA and Western blotting. Cell-wall preparations were generated from the bacterial pellets, which were washed twice in PBS and then resuspended in $300 \mu \mathrm{l}$ raffinose buffer, $50 \mu \mathrm{l}$ protease inhibitor cocktail, $5 \mu \mathrm{l}$ lysostaphin $\left(10 \mathrm{mg} \mathrm{ml}^{-1}\right)$ and $5 \mu \mathrm{l}$ DNase $\left(1 \mu \mathrm{g} \mathrm{ml}^{-1}\right)$ as described previously (Hair et al., 2008).

IgG shed from S. aureus in the presence of protease inhibitors. Washed mid-exponential-phase $S$. aureus was coated with IgG as described above, washed and incubated in $0.5 \mathrm{ml}$ PBS (control) or $0.5 \mathrm{ml}$ protease inhibitor (cocktail or individual protease inhibitor) at $37{ }^{\circ} \mathrm{C}$ for various lengths of time. IgG spontaneously shed from the surface was recovered in the supernatant and assayed by ELISA and Western blot.

IgG-mediated complement activation. Bacteria coated with IgG were prepared as described above. After centrifugation, pellets were resuspended in $1 \mathrm{ml} \mathrm{GVBS}{ }^{2+}$. Of this suspension, $200 \mu \mathrm{l}$ was combined with $\mathrm{GVBS}^{2+}$ and serum to achieve a volume of $1 \mathrm{ml}$ with a $2 \%$ final concentration of serum. Samples were incubated at $37{ }^{\circ} \mathrm{C}$ for $10 \mathrm{~min}$, washed and centrifuged, and the pellets were stripped of C3 fragments, as described previously (Cunnion et al., 2001). Supernatants were analysed by C3 ELISA.

ELISA. Flat-bottomed Immulon 2 plates were coated with $50 \mu 1$ chicken anti-human IgG (GeneTex), diluted $1: 10000$ in a carbonate coating buffer, for $4 \mathrm{~h}$. Plates were washed three times with PBST (PBS with $0.5 \%$ Tween 20) and blocked with $3 \%$ BSA in PBST overnight at $4{ }^{\circ} \mathrm{C}$. At the time of use, plates were washed three times with PBST, and the samples were diluted in $3 \%$ BSA in PBST and allowed to incubate in the plates for $1 \mathrm{~h}$ at room temperature. Plates were washed three times with PBST and then probed with horseradish peroxidase-labelled rabbit anti-human IgG antibody (Dako) diluted $1: 10000$, for $1 \mathrm{~h}$ at $25^{\circ} \mathrm{C}$. Plates were washed three times with PBST and developed with TMB Plus (Accurate Chemical); reactions were stopped with $0.5 \mathrm{M} \mathrm{H}_{2} \mathrm{SO}_{4}$ and the $A_{450}$ was read. Purified IgG was used to generate standard curves. C3 ELISAs were performed as described previously (Cunnion et al., 2004).

IgG assays by Western blotting. Samples were reduced with SDS sample buffer containing 5\% 2-mercaptoethanol, unless otherwise stated, and boiled for $5 \mathrm{~min}$ before loading onto $4-20 \%$ gradient SDS-PAGE mini-gels (Bio-Rad). Semi-dry transfer was performed onto a PVDF membrane. The membrane was blocked with $3 \%$ BSA in Tris-buffered saline with $0.1 \%$ Tween 20 , washed and probed with chicken anti-IgG (diluted 1:5000). The membrane was washed four times for $5 \mathrm{~min}$ each, probed with horseradish peroxidase-labelled anti-chicken antibody (diluted 1:5000), washed and developed using enhanced chemiluminescence. Digital images were captured using VersaDoc (Bio-Rad).

Phagocytosis assay. Human neutrophils were prepared using heparinized human blood from healthy human volunteers by Hypaque-Ficoll step gradient centrifugation, dextran sedimentation and hypotonic lysis, as described previously (Cunnion et al., 2005). One millilitre of washed exponential-phase bacteria $\left(1 \times 10^{9}\right.$ cells $\mathrm{ml}^{-1}$ ) was combined with $100 \mu \mathrm{l}$ purified $\operatorname{IgG}\left(1 \mathrm{mg} \mathrm{ml}^{-1}\right)$ and incubated at room temperature for $5 \mathrm{~min}$ and then washed twice with EDTA-GVBS $^{2-}$. Pellets were resuspended in either $500 \mu$ l protease inhibitor cocktail or buffer control at $37{ }^{\circ} \mathrm{C}$ for $30 \mathrm{~min}$. After centrifugation, pellets were resuspended in $1 \mathrm{ml} \mathrm{GVBS}{ }^{2+}$. To $100 \mu \mathrm{l}$ of the bacterial suspension, $\mathrm{GVBS}^{2+}$ and IgG-depleted serum were added to achieve a final volume of $500 \mu \mathrm{l}$ at $2 \%$ serum. After incubation at $37^{\circ} \mathrm{C}$ for $10 \mathrm{~min}, 100 \mu \mathrm{l}$ of this suspension was combined with $800 \mu \mathrm{l}$ Hanks' balanced salt solution and $100 \mu \mathrm{l}$ purified human neutrophils to achieve a bacteria : neutrophil ratio of $20: 1$. This suspension was incubated in a rotator at $37^{\circ} \mathrm{C}$ for $45 \mathrm{~min}$. 
After the final incubation, a $100 \mu \mathrm{l}$ aliquot of the mixture was removed, stained with $5 \mu \mathrm{l}$ acridine orange $(0.01 \%$ final concentration) for $2 \mathrm{~min}$, quenched with $10 \mu \mathrm{l}$ crystal violet $(0.03 \%$ final concentration) for $10 \mathrm{~min}$ and then fixed to a microscope slide using a cytospin. Slides were blinded to the reader and evaluated by fluorescence microscopy. For each slide, 100 neutrophils were counted to determine the percentage of neutrophils phagocytosing bacteria and the total number of $S$. aureus ingested.

MS. Protein bands were excised from an SDS-polyacrylamide gel, cut into $1-2 \mathrm{~mm}$ cubes and incubated in $100 \%$ acetonitrile for $45 \mathrm{~min}$. The samples were reduced with $50 \mathrm{mM}$ dithiothreitol at $56{ }^{\circ} \mathrm{C}$ for 45 min before alkylation with $55 \mathrm{mM}$ iodoacetamide for $1 \mathrm{~h}$ at room temperature in the dark. The gel pieces were dried using a SpeedVac, rehydrated with a modified sequencing-grade trypsin solution (12.5 ng $\mathrm{Hl}^{-1}$; Promega) and incubated for $45 \mathrm{~min}$ in an ice bath. The excess trypsin solution was removed and replaced with $50 \mu \mathrm{l}$ $50 \mathrm{mM}$ ammonium bicarbonate, $10 \%$ acetonitrile $(\mathrm{pH} \mathrm{8.0)}$ and the mixture was incubated overnight at $37^{\circ} \mathrm{C}$. Peptides were extracted twice with $25 \mu \mathrm{l} 50 \%$ acetonitrile, $5 \%$ formic acid. The eluates were pooled and dried in a SpeedVac. The dried peptides were resuspended in $20 \mu \mathrm{l}$ Buffer $\mathrm{A}$ ( $5 \%$ acetonitrile, $0.1 \%$ formic acid, $0.005 \%$ heptafluorobutyric acid) and loaded onto a $12 \mathrm{~cm} \times 0.075 \mathrm{~mm}$ fused silica capillary column packed with $5 \mu \mathrm{m}$ diameter C-18 beads (The Nest Group). Peptides were eluted over 55 min by applying a $0-80 \%$ linear gradient of Buffer B (95\% acetonitrile, $0.1 \%$ formic acid and $0.005 \%$ heptafluorobutyric acid) at a final flow rate of approximately $200 \mathrm{nl} \mathrm{min}{ }^{-1}$ directly into the source. To acquire more tandem MS (MS/MS) spectra, the gradient was extended to $150 \mathrm{~min}$ in some analyses. The MS data were acquired in an LT Linear Ion Trap mass spectrometer (ThermoFinnigan) using an automated scan mode. The methods and instrument settings were as follows. A single segment and five data-dependent scan events with a full MS scan, followed by four MS/MS scans of the highest-intensity ions, were carried out. Normalized collision energy was set at 35 , activation Q was 0.250 with minimum full scan signal intensity at $1 \times 10^{5}$ with no minimum $\mathrm{MS}^{2}$ intensity specified. Dynamic exclusion was turned on utilizing a 3 min repeat count of 2 with the mass width set at $1.0 \mathrm{~m} / z$. The generated MS data were used for database searches using the MASCOT search engine (version 2.2.03; Matrix Sciences). The MS/MS data were searched using the latest version of the indexed combined Homo sapiens and S. aureus non-redundant protein database from SwissProt. The following parameters were used for the searches: carbamidomethylation of cysteine as the fixed modification and oxidized methionine and deamidation of asparagine and glutamine as variable modifications. Precursor tolerance was set to 75 p.p.m. and the MS/MS fragment tolerance to $0.8 \mathrm{Da}$. Peptide scores $>30$ and an expect score $<0.05$ were considered to be significant.

\section{RESULTS}

\section{Bound IgG is shed from the $S$. aureus surface over time}

We first tested whether IgG bound to the $S$. aureus surface remained constant or decreased over time. After purified IgG was allowed to bind to the staphylococcal surface, the opsonized bacteria were washed and incubated in buffer. Bacteria were recovered and cell-wall preparations were generated and analysed under non-reducing conditions by Western blotting with anti-human IgG antibodies. We found that the amount of IgG that remained bound to the $S$. aureus surface decreased over time (Fig. 1a). We also measured the amount of $\operatorname{IgG}$ that remained bound to the $S$. aureus surface over time by ELISA. After an initial $17 \%$ decrease in the first minute, we found a further slower decrease resulting in a cumulative loss of $38 \%$ of bound IgG over $30 \mathrm{~min}(P=0.02)$ (Fig. 1b). These experiments suggested that human IgG is efficiently removed from the $S$. aureus surface. We then tested IgG release from the $S$. aureus surface into the surrounding buffer by ELISA (Fig. 1c) and demonstrated an initial shedding of $90 \mathrm{ng} \mathrm{ml}^{-1}$ in the first minute, followed by a slower shedding of up to $262 \mathrm{ng} \mathrm{ml}{ }^{-1}$ by $30 \mathrm{~min}(P=0.05)$. Western blot analysis (non-reducing conditions) of IgG shed into the surrounding buffer (Fig. 1d) confirmed the ELISA findings. Thus, increasing amounts of immunoglobulin were shed from the bacterial surface over $30 \mathrm{~min}$ in the absence of other serum proteins.

We then compared live $S$. aureus with gently heat-killed bacteria $\left(70{ }^{\circ} \mathrm{C}\right.$ for $\left.12 \mathrm{~min}\right)$. Both were coated with IgG, washed and assayed for IgG fragment shedding by Western blotting. Interestingly, when analysed under reducing conditions (Fig. 1e), the $\operatorname{IgG}$ shed from live bacteria revealed novel sizes that were not evident for the dead bacteria. These novel bands were not present for control blots stained with secondary antibody alone. Some of these IgG-containing bands, at approximately 90 and $130 \mathrm{kDa}$, were larger than the IgG heavy chain. Additional fragments of approximately 18 and $20 \mathrm{kDa}$ were also identified that were smaller than the IgG light chain. IgG fragments shed from the heat-killed bacteria did not include these novel fragment sizes. These findings suggest that, unlike dead $S$. aureus, live $S$. aureus can cleave surface-bound IgG into uniquely sized fragments, possibly mediated by staphylococcal proteases.

In order to confirm that the shed $130 \mathrm{kDa}$ band identified in the Western blot contained IgG fragments, we performed MS. The $130 \mathrm{kDa}$ band was excised from total protein-stained SDS-polyacrylamide gels and processed for analysis by liquid chromatography-MS/MS. The peptides identified are shown in Table 1. Nine distinct peptide sequences from IgG were identified, confirming that unique-sized IgG-containing complexes were shed from the $S$. aureus surface.

\section{Protease inhibitors block IgG cleavage from S. aureus}

We tested whether IgG shedding from the S. aureus surface could be inhibited by using a mixture of broadspectrum protease inhibitors. After coating with human IgG and washing, bacteria were incubated in buffer with and without protease inhibitor cocktail. The amount of IgG cleaved and shed into the surrounding buffer, analysed by Western blotting (non-reducing conditions), appeared markedly decreased in the presence of protease inhibitors (Fig. 2a). We then performed ELISA quantification of IgG fragments shed from the $S$. aureus surface (Fig. 2b), which showed that, by $5 \mathrm{~min}$, the amount of IgG released from the S. aureus surface was 
(a)

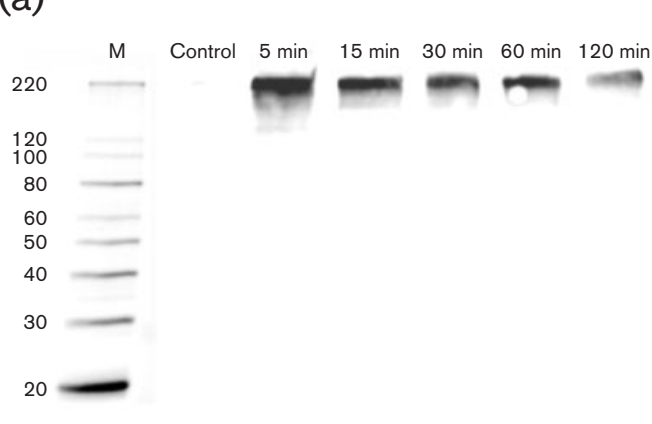

(c)

(e)
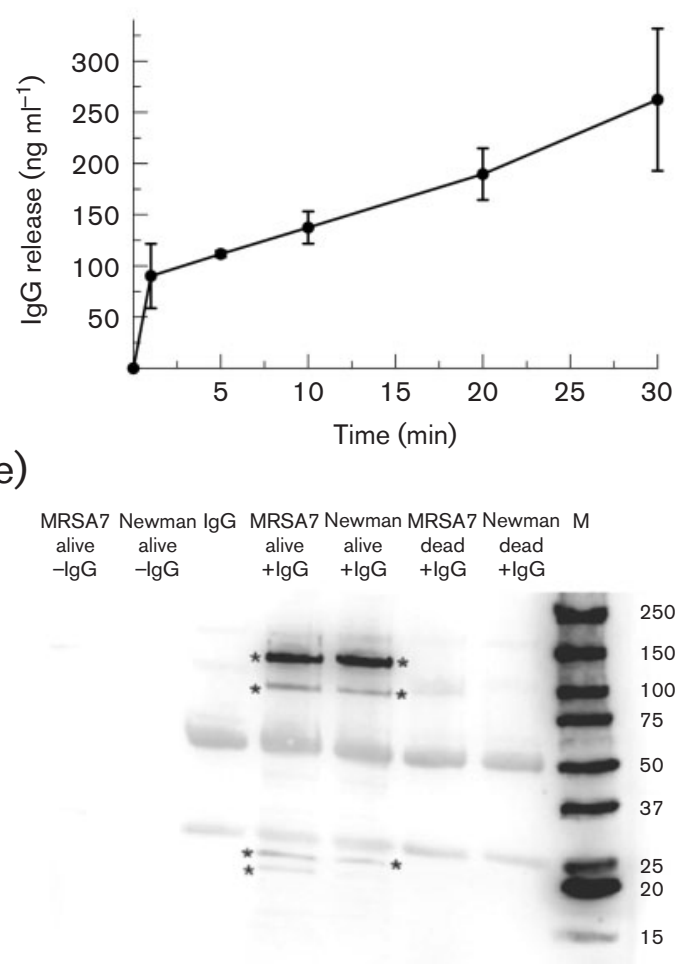

(b)

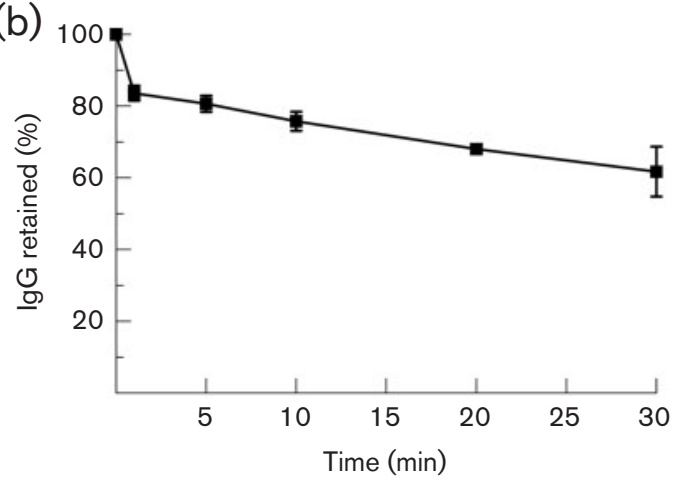

(d)

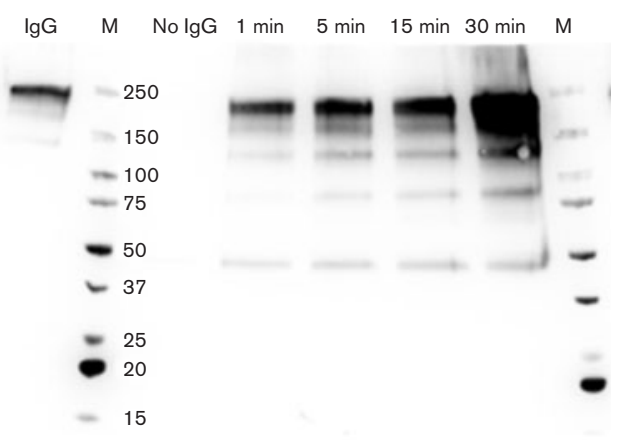

Fig. 1. Surface-bound IgG is shed from $S$. aureus. $(a, b) S$. aureus was incubated with purified pooled human IgG, washed and incubated in buffer. Cell-wall preparations, containing surface-bound lgG, were generated for each time point, processed under non-reducing conditions and analysed by Western blotting (a) and ELISA (b). Data are means \pm SEM of three independent experiments. (c, d) S. aureus was coated with $\mathrm{lgG}\left(0.002 \mathrm{mg} \mathrm{ml}^{-1}\right.$ final concentration) for 5 min, washed and then incubated in buffer. IgG fragments shed into the surrounding buffer were analysed by ELISA (c) and Western blotting under non-reducing conditions (d). Data are means \pm SEM of three independent experiments. (e) A clinical MRSA strain (MRSA7) and strain Newman, either live in exponential phase or gently heat-killed, were incubated with $\lg G(+\lg G)$ or buffer control (-lgG). Shed lgG fragments were processed under reducing conditions and analysed by Western blotting. IgG heavy $(\sim 50 \mathrm{kDa})$ and light $(\sim 25 \mathrm{kDa})$ chains were detectable at the appropriate positions. The lgG-containing complexes that did not migrate as heavy or light chains are indicated by asterisks. M, Molecular mass marker $(\mathrm{kDa})$.

17-fold greater for the control compared with those treated with protease inhibitors $(P<0.01)$. These findings showed that the shedding of IgG from the $S$. aureus surface could be blocked by protease inhibitors and suggested that the shedding of IgG is mediated by staphylococcal proteases.

\section{Serine and cysteine protease inhibitors decrease the cleavage of bound IgG}

S. aureus proteases belong to three broad categories: metalloproteases, serine proteases and cysteine proteases. After coating with human IgG and washing, S. aureus was 
Table 1. MS of the $\sim 130 \mathrm{kDa}$ lgG fragment shed from the $S$. aureus surface

\begin{tabular}{|c|c|c|c|c|c|}
\hline $\begin{array}{l}\text { Expected } \\
\text { molecular } \\
\text { mass (Da) }\end{array}$ & $\begin{array}{l}\text { Calculated } \\
\text { molecular } \\
\text { mass (Da) }\end{array}$ & $\begin{array}{l}\text { Peptide } \\
\text { score }\end{array}$ & Expect score & Peptide sequence $^{\star}$ & IgG chain region \\
\hline 2138.6674 & 2138.0202 & 110 & $6.6 \times 10^{-8}$ & R.TPEVTCVVVDVSHEDPEVK.F & Heavy $-\mathrm{C}_{\mathrm{H}} 2$ \\
\hline 2543.6954 & 2543.1241 & 122 & $4.7 \times 10^{-9}$ & K.GFYPSDIAVEWESNGQPENNYK.T & Heavy $-\mathrm{C}_{\mathrm{H}} 3$ \\
\hline 3815.5432 & 3814.8148 & 76 & 0.00012 & T.KNQVSLTCLVKGFYPSDIAVEWESNGQPENNYK.T & Heavy $-\mathrm{C}_{\mathrm{H}} 3$ \\
\hline 3620.9002 & 3620.6701 & 121 & $3.5 \times 10^{-9}$ & K.VDNALQSGNSQESVTEQDSKDSTYSLSSTLTLSK.A & Light $-\mathrm{C}$ region \\
\hline 1743.1218 & 1742.8515 & 73 & 0.00034 & K.YAASSYLSLTPEQWK.S & Light $-\mathrm{C}$ region \\
\hline 2139.6274 & 2138.9678 & 52 & 0.048 & R.TPEVTCVVVDVSHEDPEVQ.F & Heavy $-\mathrm{C}_{\mathrm{H}} 2$ \\
\hline 2555.8897 & 2555.1414 & 67 & 0.0014 & P.ENNYKTTPPMLDSDGSFFLYSK.L & Heavy $-\mathrm{C}_{\mathrm{H}} 3$ \\
\hline
\end{tabular}

${ }^{\star}$ The amino acid before and after the dot indicates the amino acid that precedes or follows that of the detected peptide in the normal full sequence of the protein.

incubated with specific protease inhibitors for each protease group at concentrations recommended by the manufacturer (Roche). Shed IgG fragments were processed under reducing conditions and analysed by Western blotting to identify changes in the different sizes of IgG
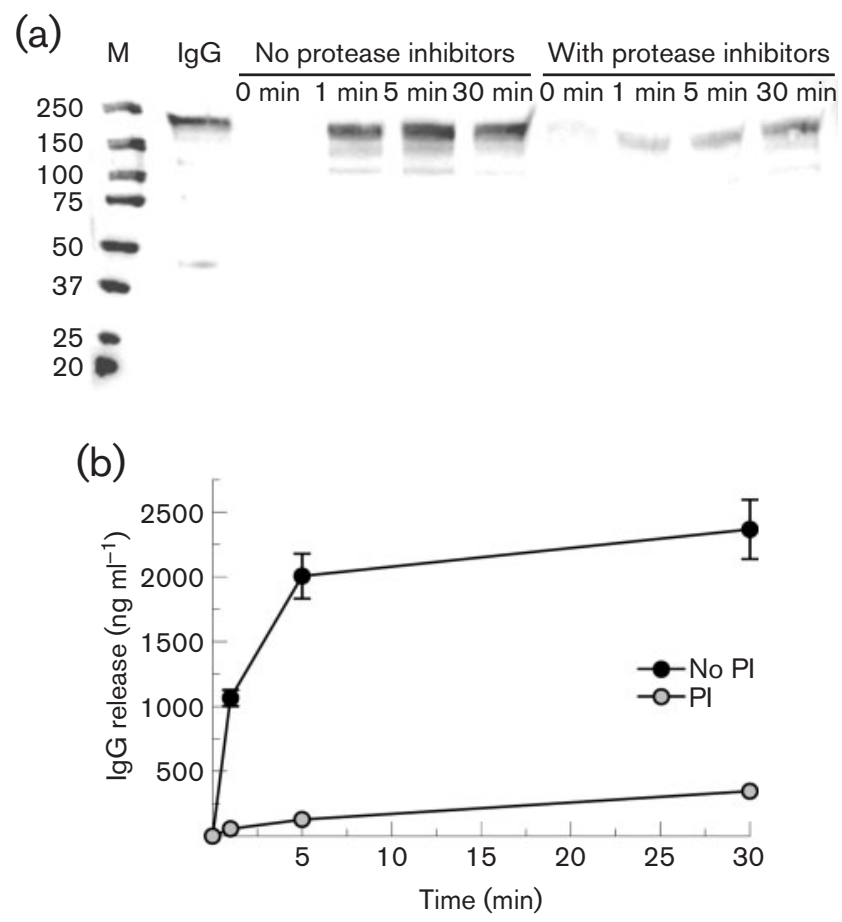

Fig. 2. Inhibition of shedding of $S$. aureus-bound IgG by broadspectrum protease inhibitors. $S$. aureus was coated with $\lg G$ (0.1 $\mathrm{mg} \mathrm{ml}^{-1}$ final concentration), incubated with broad-spectrum protease inhibitors (PI) or buffer control (no PI) and analysed by Western blotting under non-reducing conditions (a) and ELISA (b). Data are means \pm SEM of three independent experiments. $M$, Molecular mass marker (kDa). fragments. Testing of the serine protease inhibitors PMSF (Fig. 3a), Pefabloc (results not shown) and aprotinin (Fig. 3b) showed partial inhibition of IgG shedding for each as the concentrations of the protease inhibitor increased. Testing of the cysteine protease inhibitors E-64 (Fig. 3c) and $\mathrm{N}$-ethylmaleimide (results not shown) also showed partial inhibition of IgG fragment shedding for each as the concentrations of the protease inhibitors increased. Testing of metalloprotease inhibition was performed with EDTA (Fig. 3d) and no inhibition of IgG shedding was demonstrated. These findings suggested that staphylococcal serine proteases or cysteine proteases, or both, may contribute to IgG cleavage from the $S$. aureus surface.

\section{Blocking IgG cleavage with protease inhibitors increases C3-fragment deposition on S. aureus}

To determine whether the cleavage of S. aureus-bound IgG by staphylococcal proteases would affect complement activation and opsonization by $\mathrm{C} 3 \mathrm{~b} / \mathrm{iC} 3 \mathrm{~b}$, we coated bacteria with IgG and then allowed them to incubate in the presence or absence of a protease inhibitor cocktail. After washing, S. aureus was incubated with normal human serum, washed and stripped of bound C3 fragments, which were measured by ELISA. Under both conditions, bound C3 fragments were noted to become saturated at the same value by $120 \mathrm{~min}$. However, at $30 \mathrm{~min}$, a $49.4 \%$ increase in C3-fragment binding was noted for bacteria treated with protease inhibitors compared with buffer control $(P=0.03)$ (Fig. 4). Because normal human serum contains IgG, we repeated these experiments using IgG-depleted serum instead of normal human serum. IgG-coated $S$. aureus incubated with protease inhibitor cocktail, washed and then incubated with IgG-depleted serum bound $492 \pm 99 \mathrm{ng}$ C3 $\mathrm{ml}^{-1}$ compared with binding of $267 \pm 40 \mathrm{ng} \mathrm{C} 3 \mathrm{ml}^{-1}$ with no protease inhibitors. Thus, using protease inhibitors to inhibit the cleavage of IgG resulted in an $84.3 \%$ increase in $\mathrm{C} 3$-fragment binding to bacteria compared with buffer control $(P=0.04)$. These 
(a)

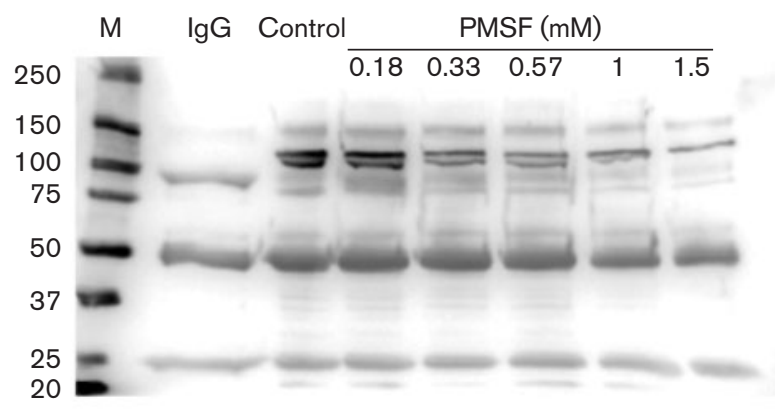

(c)

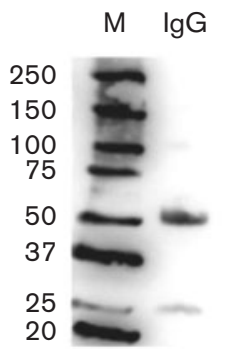

Control

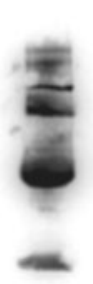

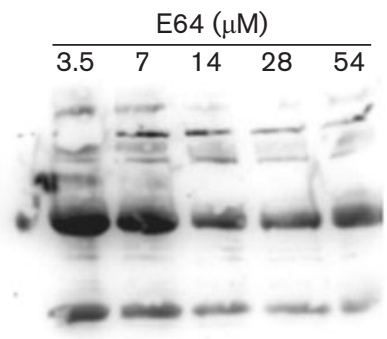

(b)

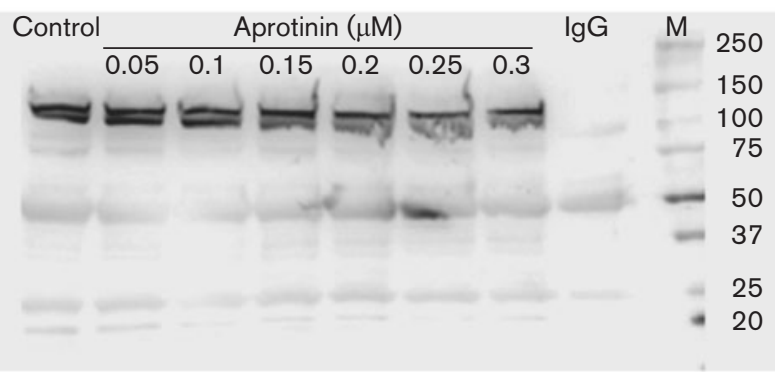

(d)

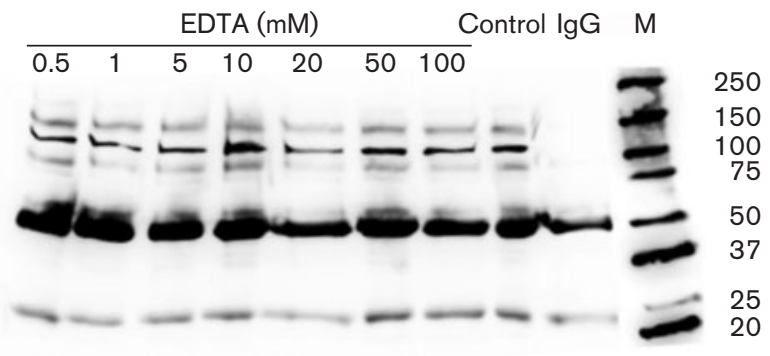

Fig. 3. Inhibition of shedding of $S$. aureus-bound IgG by class-specific protease inhibitors. Increasing amounts of class-specific protease inhibitors were incubated with IgG-coated $S$. aureus for $30 \mathrm{~min}$ and the shed IgG fragments were analysed by Western blotting under reducing conditions. The serine protease inhibitors tested were PMSF (a) and aprotinin (b); E-64 was used as a cysteine protease inhibitor (c); and EDTA was used as a metalloprotease inhibitor (d). M, Molecular mass marker (kDa).

findings suggested that cleavage of surface-bound IgG by staphylococcal proteases reduces C3-fragment opsonization by IgG-mediated complement activation.

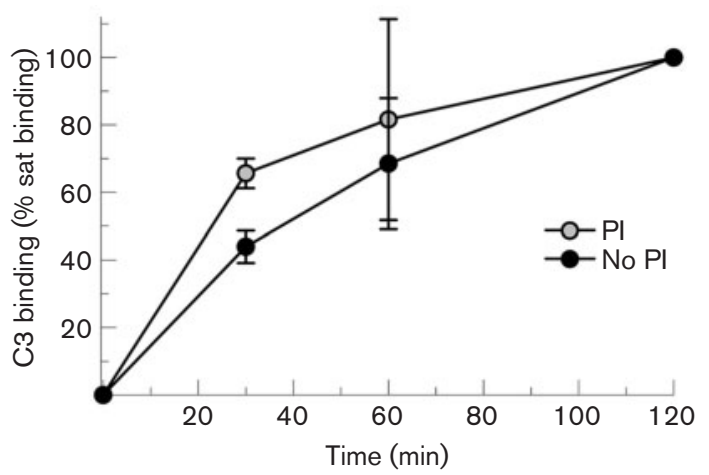

Fig. 4. Inhibition of IgG cleavage by protease inhibitors increases C3-fragment binding to $S$. aureus. IgG-coated $S$. aureus was incubated with broad-spectrum protease inhibitors $(\mathrm{PI})$ or buffer control (no Pl), washed and incubated with normal human serum for 0, 30, 60 and $120 \mathrm{~min}$. Bound $\mathrm{C} 3$ fragments were stripped and measured by ELISA. Data are means \pm SEM of four independent experiments.

\section{Blocking IgG cleavage increases $S$. aureus binding to neutrophils and phagocytosis}

To determine whether the cleavage of IgG on the S. aureus surface affects binding to neutrophils and phagocytosis, we performed the following experiments. S. aureus was coated with IgG as described above, incubated in the presence or absence of protease inhibitors, washed and incubated with purified human neutrophils. Bacteria were stained with acridine orange and adhered to slides using a cytospin. The number of adherent bacteria per 100 neutrophils was counted by fluorescence microscopy. After subtracting the background non-IgG-mediated binding, treatment with protease inhibitors led to $114 \pm 14$ bacteria associated per neutrophil compared with binding of $64 \pm 22$ bacteria with no protease inhibitors. Thus, using protease inhibitors to inhibit IgG cleavage increased $S$. aureus binding to neutrophils by 1.8 -fold $(P=0.04)$. In order to better understand the full impact of IgG cleavage on $S$. aureus phagocytosis, we next coated bacteria with $\mathrm{IgG}$ as described above, incubated them in the presence or absence of protease inhibitors, and washed and incubated them with IgG-depleted serum (2\%). IgG-depleted serum contains active complement components, therefore permitting complement-mediated opsonization to occur, as well as the generation of complement anaphylatoxins (e.g. C5a). To these suspensions, purified human neutrophils were 
added. IgG-coated $S$. aureus incubated with protease inhibitors was phagocytosed at a ratio of $78 \pm 15$ bacteria per 100 neutrophils compared with phagocytosis of $20 \pm 5$ bacteria per 100 neutrophils with no protease inhibitors. Thus, phagocytosis by neutrophils increased fourfold for IgG-coated bacteria treated with protease inhibitors compared with the control $(P=0.02)$. Measuring the number of neutrophils phagocytosing bacteria per 100 neutrophils showed that, for IgG-coated bacteria incubated with protease inhibitors, $41 \pm 5$ neutrophils phagocytosed bacteria compared with $15 \pm 2$ with no protease inhibitors. Thus, using protease inhibitors to limit IgG cleavage increased the number of neutrophils phagocytosing bacteria by 2.7 -fold compared with the control $(P=0.01)$. It is possible that residual protease inhibitors present on addition of serum could contribute to the differences in phagocytosis efficiency. However, such a contribution is likely to be minimal due to the large amount of protein in the serum, which should overwhelm minute amounts of residual protease inhibitors. Overall, these findings suggested that blocking the cleavage of surface-bound $\operatorname{IgG}$ using protease inhibitors increased binding to neutrophils and dramatically improved phagocytosis efficiency.

\section{DISCUSSION}

Previous studies have shown that human immunoglobulins can be cleaved by several bacterial proteases. Fick et al. (1985) published a study that showed the IgG proteolytic activity of Pseudomonas aeruginosa isolated from patients with cystic fibrosis, whilst Molla et al. (1988) demonstrated cleavage of IgG and IgA by proteases from Serratia marcescens (Molla et al., 1988). Later, Prokesová et al. $(1992,1995)$ showed that a serine protease from S. aureus was able to cleave human IgG, IgM and IgA in solution. Loomes et al. (1993) also demonstrated IgG cleavage in vitro and in vivo by Proteus mirabilis proteases. More recently, several studies identified the cysteine proteases IdeS and SpeB from Streptococcus pyogenes, which cleave host IgG (von Pawel-Rammingen \& Björck, 2003). To our knowledge, the current study is unique in evaluating the shedding of human IgG bound to the S. aureus surface.

The experiments in this study showed that significant amounts of IgG are shed from the surface of $S$. aureus over $30 \mathrm{~min}$. As noted above, previous investigators have shown that an $S$. aureus protease can cleave human immunoglobulins in solution; however, our results suggested that staphylococcal proteases are also active in cleaving $S$. aureus-bound IgG. The efficient cleavage of $S$. aureusbound IgG occurred in the absence of serum proteins and therefore could not have been due to staphylokinase interaction with plasminogen. It is also possible that the protease activity may cleave the $S$. aureus surface components to which the IgG attaches. However, it seems likely that the majority of IgG shedding results from activity towards the IgG itself, given that the $\operatorname{IgG}$ is shed in fragments and it has been shown by other investigators that unbound $\operatorname{IgG}$ can be cleaved by staphylococcal protease.

Of the classes of protease known to be secreted by $S$. aureus, serine and cysteine protease inhibitors appeared to decrease IgG cleavage. Metalloprotease inhibitor did not appear to have any effect. None of the individual protease inhibitors appeared to inhibit IgG cleavage as efficiently as the broad-spectrum protease inhibitor cocktail. These findings suggest that serine proteases probably play a role in the cleavage of surface-bound IgG and raise the possibility that cysteine proteases may also contribute to this process.

Our most important goal in these studies was to evaluate whether blocking the shedding of $S$. aureus-bound IgG would alter the host defence functions of immunoglobulin. Using a cocktail of protease inhibitors to decrease the cleavage of surface-bound IgG, these studies showed that complement activation and $\mathrm{C} 3 \mathrm{~b} / \mathrm{iC} 3 \mathrm{~b}$ deposition was increased, binding to neutrophils was increased and phagocytosis efficiency was increased fourfold. These studies suggest that the shedding of $S$. aureus-bound immunoglobulin inhibits normal immunoglobulin-mediated host defence functions and thus probably contributes to host defence evasion. These studies suggest that inhibition of staphylococcal protease-mediated IgG cleavage could be a viable strategy to improve host control of $S$. aureus.

\section{ACKNOWLEDGEMENTS}

This work was conducted with support from The Children's Hospital of The King's Daughters Research Endowment. PFGE was kindly performed by Dr E. Stephen Buescher, Eastern Virginia Medical School, Norfolk, VA, USA.

\section{REFERENCES}

Boles, B. R. \& Horswill, A. R. (2008). agr-mediated dispersal of Staphylococcus aureus biofilms. PLoS Pathog 4, e1000052.

Brown, E. J., Hosea, S. W., Hammer, C. H., Burch, C. G. \& Frank, M. M. (1982). A quantitative analysis of the interactions of antipneumococcal antibody and complement in experimental pneumococcal bacteremia. J Clin Invest 69, 85-98.

Cunnion, K. M., Lee, J. C. \& Frank, M. M. (2001). Capsule production and growth phase influence binding of complement to Staphylococcus aureus. Infect Immun 69, 6796-6803.

Cunnion, K. M., Hair, P. S. \& Buescher, E. S. (2004). Cleavage of complement $\mathrm{C} 3 \mathrm{~b}$ to $\mathrm{iC} 3 \mathrm{~b}$ on the surface of Staphylococcus aureus is mediated by serum complement factor I. Infect Immun 72, 28582863.

Cunnion, K. M., Buescher, E. S. \& Hair, P. S. (2005). Serum complement factor I decreases Staphylococcus aureus phagocytosis. J Lab Clin Med 146, 279-286.

El-Gilany, A. H. \& Fathy, H. (2009). Risk factors of recurrent furunculosis. Dermatol Online J 15, 16.

Fick, R. B., Jr, Baltimore, R. S., Squier, S. U. \& Reynolds, H. Y. (1985). IgG proteolytic activity of Pseudomonas aeruginosa in cystic fibrosis. $J$ Infect Dis 151, 589-598. 
Hair, P. S., Ward, M. D., Semmes, O. J., Foster, T. J. \& Cunnion, K. M. (2008). Staphylococcus aureus clumping factor A binds to complement regulator factor I and increases factor I cleavage of C3b. J Infect Dis 198, 125-133.

Joiner, K. A., Goldman, R. C., Hammer, C. H., Leive, L. \& Frank, M. M. (1983). Studies on the mechanism of bacterial resistance to complement-mediated killing. VI. IgG increases the bactericidal efficiency of C5b-9 for E. coli 0111B4 by acting at a step before C5 cleavage. J Immunol 131, 2570-2575.

Klein, E., Smith, D. L. \& Laxminarayan, R. (2007). Hospitalizations and deaths caused by methicillin-resistant Staphylococcus aureus, United States, 1999-2005. Emerg Infect Dis 13, 1840-1846.

Leijh, P. C., van den Barselaar, M. T., Daha, M. R. \& van Furth, R. (1981). Participation of immunoglobulins and complement components in the intracellular killing of Staphylococcus aureus and Escherichia coli by human granulocytes. Infect Immun 33, 714-724.

Loomes, L. M., Kerr, M. A. \& Senior, B. W. (1993). The cleavage of immunoglobulin $\mathrm{G}$ in vitro and in vivo by a proteinase secreted by the urinary tract pathogen Proteus mirabilis. J Med Microbiol 39, $225-232$.
Molla, A., Kagimoto, T. \& Maeda, H. (1988). Cleavage of immunoglobulin $\mathrm{G}$ (IgG) and IgA around the hinge region by proteases from Serratia marcescens. Infect Immun 56, 916-920.

Peterson, P. K., Verhoef, J., Sabath, L. D. \& Quie, P. G. (1977). Effect of protein A on staphylococcal opsonization. Infect Immun 15, 760-764.

Prokesová, L., Potuzníková, B., Potempa, J., Zikán, J., Radl, J., Hachová, L., Baran, K., Porwit-Bobr, Z. \& John, C. (1992). Cleavage of human immunoglobulins by serine proteinase from Staphylococcus aureus. Immunol Lett 31, 259-265.

Prokesová, L., Potuzníkovà, B., Potempa, J., Zikán, J., Radl, J., PorwitBóbr, Z. \& John, C. (1995). Cleavage of human immunoglobulins by proteinase from Staphylococcus aureus. Adv Exp Med Biol 371A, 613-616.

Rogers, B. A., Drake, A. K. \& Spelman, D. (2009). Methicillin resistant Staphylococcus aureus endocarditis in an Australian tertiary hospital: 1991-2006. Heart Lung Circ 18, 208-213.

Rooijakkers, S. H., van Wamel, W. J., Ruyken, M., van Kessel, K. P. \& van Strijp, J. A. (2005). Anti-opsonic properties of staphylokinase. Microbes Infect 7, 476-484.

von Pawel-Rammingen, U. \& Björck, L. (2003). IdeS and SpeB: immunoglobulin-degrading cysteine proteinases of Streptococcus pyogenes. Curr Opin Microbiol 6, 50-55. 